\title{
Effect of A Group Tobacco Cessation Behavioural Intervention Among Patients with Mental Illness in Kenya: Results from a Controlled Clinical Trial
}

Yvonne Olando ( $\nabla$ yvonneolando@yahoo.com )

University of Nairobi

Muthoni Mathai

University of Nairobi

Mary Kuria

University of Nairobi

Francis Njiri

University of Nairobi

Mark Huffman

Northwestern University Feinberg School of Medicine, United States

\section{Research Article}

Keywords: Smoking cessation, smoking reduction, group behavioural therapy, mental illness

Posted Date: December 17th, 2020

DOI: https://doi.org/10.21203/rs.3.rs-112872/v1

License: (9) This work is licensed under a Creative Commons Attribution 4.0 International License.

Read Full License 


\section{Abstract}

Background: Individuals with mental disorders are more susceptible to initiating and sustaining tobacco use; unfortunately, most do not get support to quit. Group behavioural counselling, an effective low-cost strategy for cessation has been shown to be effective, yet has not been studied among this population in Kenya.

Methods: Mentally ill tobacco users at Mathari Referral and Teaching Hospital's Clinic for Substance Abuse Treatment in Nairobi, were recruited from September 2017-March 2019. Participants were allocated into intervention and control groups (1:1). Intervention group participants met in groups of 10 over 24-weeks to participate in group behavioural counselling sessions using a structured curriculum to promote cessation. Control group participants received usual care. The primary outcome was tobacco cessation at 24-weeks measured through salivary cotinine strips. Secondary outcomes included selfreported number of cigarettes/sticks used daily and health-related quality of life (HRQoL), using the WHOQoL Brief Questionnaire at 24-weeks. Between-group event rates were compared using Cox proportional hazards models, while differences in HRQoL scores were analysed using paired t-tests.

Results: Participants' mean age was $35(\mathrm{SD}=9)$ years, $87 \%$ were male, and $42 \%$ had completed secondary education. Over half (65\%) had substance use disorders (diagnosed) and 15\% had major depressive disorders. Most participants (94\%) used cigarettes at baseline and participants smoked for a mean of 13 $(S D=11)$ years with an average of $14(S D=7)$ sticks daily. Intervention group participants reported a higher cessation rate $(15.2 \%$ vs. $0 \%$ at week $12 ; \mathrm{P}=0.02$ and $9.1 \%$ vs. $0 \% ; \mathrm{P}=0.10)$ at 24 -weeks, with a lower number of sticks smoked ( $97 \%$ vs. $58.6 \%$; $\mathrm{P}<0.0001)$ compared with control group participants at 24weeks follow-up. Intervention group participants reported higher change in HRQoL scores compared to control participants in physical (30.6\% vs. $10.4 \%$;OR=3.79 [95\% $\mathrm{Cl}, 1.25-11.48])$ and environmental domains (34.7\% vs. $8.3 \%$;OR=5.84 [95\% $\mathrm{Cl}, 1.79-19.03])$ at end of study.

Conclusion: The group behavioural intervention among tobacco using Kenyans with mental illness led to improved tobacco cessation outcomes.

\section{Trial registration number: NCT04013724}

\section{Introduction}

The prevalence rate of major mental disorders among adults in Kenya is at 4\%. [1]. Tobacco use is also common in Kenya; 2.5 million adults (11.6\% of adults, $19.1 \%$ of men, and $4.5 \%$ of women) reported using tobacco in the 2014 Global Adults Tobacco Survey-Kenya (GATS) [2], which was the highest prevalence in sub-Saharan Africa [3]. Individuals with serious mental disorders use tobacco more [4], present with more intensive psychiatric symptoms, poorer health outcomes, and greater functional deterioration when compared to non-tobacco users [5]. They smoke at twice to quadruple the rate of the general population [6]. 
The harmful effects of tobacco use have been widely recorded, with tobacco-related illnesses including cancer, heart disease, and lung disease being among the most common mortality causes of all persons and those with mental illness [7]. Tobacco cessation reduces the risk of early death and improves healthrelated quality of life [8]. The Kenya National Tobacco Control Action Plan [9] and National Tobacco Treatment and Dependence Clinical Guidelines [10] recognize the availability of smoking cessation support as a key intervention, with provision of brief advice by healthcare providers to recommend tobacco cessation identified as an effective intervention to motivate and support patients' quit attempts.

Despite the well-known hazards of tobacco use and benefits of cessation, implementation of evidencebased interventions for tobacco cessation is limited among patients with mental illness in Kenya. Further, patients and healthcare providers have limited knowledge and practice on how to treat tobacco dependence in this context [11]. The relatively high costs of tobacco cessation pharmacotherapies [12] and limited number of trained healthcare workers to treat tobacco dependence in Kenya as a whole, suggest that alternative strategies are needed to promote cessation [13].

Therefore, this study sought to evaluate the effect of a group tobacco cessation behavioural intervention on cessation and health-related quality of life among tobacco using patients with concomitant mental illnesses at 24-weeks.

\section{Methods}

\section{Study Design}

We used a controlled clinical trial design at Mathari Referral and Teaching Hospital Clinic for Substance Abuse Treatment (CSAT) and outpatient follow-up clinics. Mathari Referral and Teaching Hospital is Kenya's only national referral and teaching psychiatric hospital with a capacity of 700 psychiatry beds. However, tobacco cessation counselling is not routinely provided (patients are not routinely offered brief tobacco cessation intervention or offered NRTs or cessation medication). The Kenyatta National Hospital/University of Nairobi Ethics review committee (KNH/UON ERC) and the National Commission for Science Technology and Innovation ethics committees approved the protocol, which was registered at clinicaltrials.gov (NCT04013724). The protocol has been published [14]. All participants provided written informed consent after receiving a complete description of the study.

\section{Participants/Sample}

Adults (aged $\geq 18$ ) with a history of tobacco use for more than six months, high nicotine dependence measured by a Fagerstrom score of $\geq 6$, ongoing outpatient follow-up for a diagnosed mental health condition (such as substance use disorder, depression, anxiety, schizophrenia and bipolar), and willingness to participate in the study for six months were eligible. Patients who were on nicotine replacement therapy (NRT) or other pharmacotherapy for tobacco cessation, and those currently experiencing severe psychotic episodes as determined by their treating mental health care provider, and those who would not consistently participate in the group sessions for whatever reason, were excluded 
from the study. Study staff recruited participants through presentation at CSAT and outpatient follow up clinics.

\section{Randomization and Blinding}

From September 2017 to March 2019, participants were recruited in groups of 10 for assignment into the intervention and control groups. The first 10 participants formed group 1-Intervention group and the next 10 participants formed group 2-Control group. This procedure continued until all 10 groups were formed (5 intervention and 5 control groups). The intervention staff was aware of the group assignment, but the staff conducting the biochemical verification were blinded to participants' allocation.

\section{Intervention Group}

Prior to recruitment, the Principal Investigator (PI) trained two counsellors who assisted with recruitment, screening, intake, and registration. Two addiction therapists who were not hospital staff were recruited and trained by the PI to lead group tobacco cessation sessions tailored to patients with mental illness. The group behavioural tobacco cessation intervention consisted of six sessions over 12 weeks, followed by monthly group meetings from weeks 14 to 24 , which were led by the PI. The program and curriculum were adapted from the Royal Australian College of General Practitioners' Supporting Smoking Cessation Guide for Health Professionals and the World Health Organization's Strengthening Health Systems for Treating Tobacco Dependence in Primary Care training package [15-16]. The timeline and session topics covered during the program are shown in Supplementary Table 1.

\section{Follow-up Sessions}

During the study period,participants continued attending the CSAT and outpatient follow-up programs. Facilitators conducted monthly behavioural group sessions 7-9 during weeks 14-26, which included facilitating discussions on participants feelings, cessation attempts, barriers experienced and coping skills; and participants were offered support as per their individual experiences/challenges). Challenges raised were documented and practical and supportive therapy related to reported challenges was offered.

\section{Control Group Procedures}

During the study period, the control group participants continued receiving usual care (follow up for their psychiatric condition), including clinical care at CSAT. The participants responded to questionnaires for outcome assessment at the end of weeks 12 and 24. The control group was offered the intervention sessions that were offered to the intervention group at the end of the study.

\section{Outcome Measures}

Participants who reported tobacco use abstinence at weeks 12 and 24 of follow-up, and consented to a saliva test were tested using a nicotine cotinine strip (Devon Medical, Pennsylvania, USA). The primary outcome was biochemically verified tobacco cessation at week 24. Nurses working at the hospital who were blinded to treatment allocation, and were not part of the study, assessed the saliva test results. Previous tobacco cessation intervention trials,treated lack of reports of abstinence as positive cotinine 
results; as such the study treated those who did not report abstinence the same way [17]. Secondary outcomes assessed included: rates of tobacco cessation at week 12, number of quit attempts, reduction in number of cigarettes/sticks used per day at 24 weeks, and HRQOL at 24-weeks. We performed additional post hoc analyses evaluating the proportion of individuals who reduced their smoking, less than two cigarettes or kuber (smokeless tobacco), per day.

\section{Data Collection}

Socio-demographic characteristics of the study participants, such as age, sex, residence, education level, occupation, and perceived health status were reported using structured questionnaires. The type of tobacco product(s) used, daily amount of tobacco consumed, duration of use, and age of initiation to tobacco also were reported. Using the Fagerstrom test, nicotine dependency was determined and intent to quit use of tobacco products was described. Data on any other substance use, such as alcohol, cannabis and khat, including duration of use, also were collected. Psychiatric diagnoses were abstracted from participants' files. Participants' health-related quality of life was assessed using the World Health Organization (WHO) Quality of Life Brief Questionnaire at baseline and at 24-weeks follow-up [18].

\section{Statistical Analysis}

Discrete variables were summarized using frequencies and percentages, while continuous variables were summarized using measures of central tendency and dispersion such as means with standard deviations and median with inter-quartile ranges, where appropriate. Bivariate analyses were carried out to compare the intervention groups with the control groups with respect to socio-demographic characteristics, history of tobacco and substance abuse, type(s) of mental illness, and HRQOL scores at baseline and follow-up. Mann-Whitney tests were used to compare the intervention and control groups for continuous variables, and Chi-square tests were used for categorical variables [14].

Rates of tobacco cessation and reduction of tobacco use were compared between groups by Cox proportional hazard models to determine the effect of the intervention on study outcomes at 24-weeks. Logistic regression models were created to compare odds of any improvement in HRQOL from baseline to 24-week follow-up. Unadjusted and adjusted models were reported, the latter which aimed to control for independent factors associated with relapse, including age, sex, baseline tobacco use (number per day), and baseline type of mental illness. Paired t-test analyses for secondary outcomes also were performed. Imputation was not used to account for missing data, and a complete case analysis was performed. A two-sided $p<0.05$ was used to determine statistical significance without adjustments to account for multiple testing. All analyses were carried out using IBM SPSS Statistics Software, Version 24.

\section{Results}

\section{Study Participants}


The flowchart of participants, including reasons for exclusion, is shown in Fig. 1. Among the 105 participants who were screened, 97 participants were recruited: 49 participants were allocated to 1 of 5 intervention groups, and 48 were allocated to the control group. Over the 24-week study period, 35 participants were lost to follow-up, including $16(32.7 \%)$ in the intervention group and $19(39.6 \%)$ in the control group.

Participants' characteristics are reported in Table 1. There were more men allocated to the intervention group $(94 \%)$ compared with the control group $(78 \%, p=0.02)$, but the group characteristics were otherwise similar between groups. Mean (SD) age of participants was 35 (SD 9) years, and most (87\%) were male. Less than half (40\%) were unemployed with a similar number (35\%) being self-employed. Most participants (65\%) had a history of substance use disorder, while almost three-quarters (74\%) reported using other drugs. At baseline, $15 \%$ had major depression, $7 \%$ had schizophrenia, and $9 \%$ had bipolar disorder. Most participants (94\%) reported using cigarettes, with only $4 \%$ using kuber. Characteristics comparing study completers versus non-completers are reported in Supplemental Table 2, which demonstrates the similarities between the two groups. 
Table 1

Baseline socio-demographic characteristics of study participants.

\begin{tabular}{|c|c|c|c|c|}
\hline & & $\begin{array}{l}\text { Intervention } \\
\mathrm{N}=49\end{array}$ & $\begin{array}{l}\text { Control } \\
N=48\end{array}$ & $\begin{array}{l}P \\
\text { value }\end{array}$ \\
\hline \multicolumn{2}{|l|}{ Age, years, mean (SD) } & $33.4(6.0)$ & $\begin{array}{l}36.1 \\
(11.4)\end{array}$ & 0.15 \\
\hline \multicolumn{2}{|l|}{ Male sex, n (\%) } & $38(78)$ & $45(94)$ & 0.02 \\
\hline \multicolumn{2}{|c|}{ Number smoked/chewed per day, mean (SD) } & $12.9(7.0)$ & $\begin{array}{l}13.9 \\
(6.5)\end{array}$ & 0.43 \\
\hline \multicolumn{2}{|c|}{ Years using tobacco, mean (SD) } & $11.6(6.4)$ & $\begin{array}{l}12.7 \\
(10.8)\end{array}$ & 0.57 \\
\hline \multicolumn{2}{|c|}{ Age of first tobacco use, mean (SD) } & $19.5(5.3)$ & $\begin{array}{l}22.1 \\
(8.8)\end{array}$ & 0.08 \\
\hline \multicolumn{2}{|l|}{ Fagerstrom score } & $5.9(1.5)$ & $5.7(1.7)$ & 0.52 \\
\hline \multicolumn{2}{|l|}{ Primary tobacco product } & $48(98)$ & $45(94)$ & 0.30 \\
\hline \multicolumn{2}{|l|}{ Cigarette } & $1(2)$ & $3(6)$ & \\
\hline \multicolumn{5}{|l|}{ Kuber } \\
\hline \multirow[t]{5}{*}{$\begin{array}{l}\text { Primary mental health } \\
\text { disorder }\end{array}$} & Substance use disorder & $39(79.6)$ & $\begin{array}{l}26 \\
(54.2)\end{array}$ & \multirow[t]{5}{*}{0.06} \\
\hline & Major depression & $4(8.2)$ & $\begin{array}{l}11 \\
(22.9)\end{array}$ & \\
\hline & Schizophrenia & $2(4.1)$ & $5(10.4)$ & \\
\hline & Bipolar & $3(6.1)$ & $6(12.5)$ & \\
\hline & Depression & $1(2.0)$ & $0(0)$ & \\
\hline \multirow[t]{5}{*}{ Education level completed } & None & $1(2.0)$ & $0(0)$ & \multirow[t]{5}{*}{0.42} \\
\hline & Primary & $15(30.6)$ & $\begin{array}{l}14 \\
(29.2)\end{array}$ & \\
\hline & Secondary & $22(44.9)$ & $\begin{array}{l}19 \\
(39.6)\end{array}$ & \\
\hline & $\begin{array}{l}\text { College ( } 1-2 \text { years post high- } \\
\text { school) }\end{array}$ & $10(20.4)$ & $\begin{array}{l}10 \\
(20.8)\end{array}$ & \\
\hline & $\begin{array}{l}\text { University (> } 4 \text { years post high- } \\
\text { school) }\end{array}$ & $1(2.0)$ & $5(10.4)$ & \\
\hline
\end{tabular}




\begin{tabular}{|c|c|c|c|c|}
\hline & & $\begin{array}{l}\text { Intervention } \\
\mathrm{N}=49\end{array}$ & $\begin{array}{l}\text { Control } \\
N=48\end{array}$ & $\begin{array}{l}\mathrm{P} \\
\text { value }\end{array}$ \\
\hline \multirow[t]{5}{*}{ Occupation } & Unemployed & $22(44.9)$ & $\begin{array}{l}15 \\
(31.3)\end{array}$ & \multirow[t]{5}{*}{0.10} \\
\hline & Student & $3(6.1)$ & $0(0)$ & \\
\hline & Self employed & $12(24.5)$ & $\begin{array}{l}21 \\
(43.8)\end{array}$ & \\
\hline & Employed & $12(24.5)$ & $\begin{array}{l}11 \\
(22.9)\end{array}$ & \\
\hline & Retired & $0(0)$ & $1(2.1)$ & \\
\hline \multirow{3}{*}{$\begin{array}{l}\text { Self-assessed general } \\
\text { health }\end{array}$} & Poor & $7(14.3)$ & 9 (18.8) & \multirow[t]{3}{*}{0.79} \\
\hline & Fair & $20(40.8)$ & $\begin{array}{l}17 \\
(35.4)\end{array}$ & \\
\hline & Good & $22(44.9)$ & $\begin{array}{l}22 \\
(45.8)\end{array}$ & \\
\hline \multirow[t]{3}{*}{$\begin{array}{l}\text { Use of alcohol and other } \\
\text { drugs }\end{array}$} & Yes & 33 (67.3) & $\begin{array}{l}37 \\
(77.1)\end{array}$ & \multirow[t]{3}{*}{0.45} \\
\hline & No & $14(28.6)$ & \multirow{2}{*}{$\begin{array}{l}11 \\
(22.9)\end{array}$} & \\
\hline & No response & $2(4.1)$ & & \\
\hline
\end{tabular}

\section{Primary Outcome: Tobacco Cessation Rate}

For the primary study outcome, the rate of biochemically-verified tobacco cessation in the intervention group was $15.2 \%(5 / 33)$ versus $0 \%(0 / 34)$ at week $12(P=0.02)$ and $9.1 \%(3 / 30)$ versus $0 \%(0 / 29)$ at 24 weeks $(P=0.10)$. No participant in the control group successfully quit (Table 2$)$.

Table 2

Successful cessation biochemically verified at 12-week and 24-week follow-up among trial participants.

\begin{tabular}{|c|c|c|c|c|c|c|}
\hline & & \multicolumn{2}{|c|}{ Intervention } & \multicolumn{2}{|c|}{ Control } & \multirow[b]{2}{*}{ p-value } \\
\hline & & $N=33$ & $\%$ & $N=29$ & $\%$ & \\
\hline \multirow[t]{2}{*}{ Cessation at 12 -week follow-up } & No & 28 & 84.8 & 34 & 100.0 & \multirow[t]{2}{*}{0.02} \\
\hline & Yes & 5 & 15.2 & 0 & 0.0 & \\
\hline \multirow[t]{2}{*}{ Cessation at 24-week follow-up } & No & 30 & 90.9 & 29 & 100.0 & \multirow[t]{2}{*}{0.10} \\
\hline & Yes & 3 & 9.1 & 0 & 0.0 & \\
\hline
\end{tabular}




\section{Secondary Outcomes: Reduction in Tobacco Consumption}

When comparing the reduction in amount smoked at baseline to 12-week and 24-week follow-up, the intervention group reduced the number of cigarettes or kuber smoked more than the control group at week 12 (mean (SD) 3.42 (SD 3.52) sticks in the intervention group versus 11.65 (SD 5.77) sticks in the control group, $\mathrm{P}<0.001$ ) and week 24 (mean (SD) 5.78 (SD 6.37) sticks in the intervention group versus 12.17 (SD 6.89) sticks in the control group, $\mathrm{P}<0.0001$, Table 3 ).

Table 3

Amount smoked at baseline, 12-week follow-up, and 24-week follow-up among trial participants.

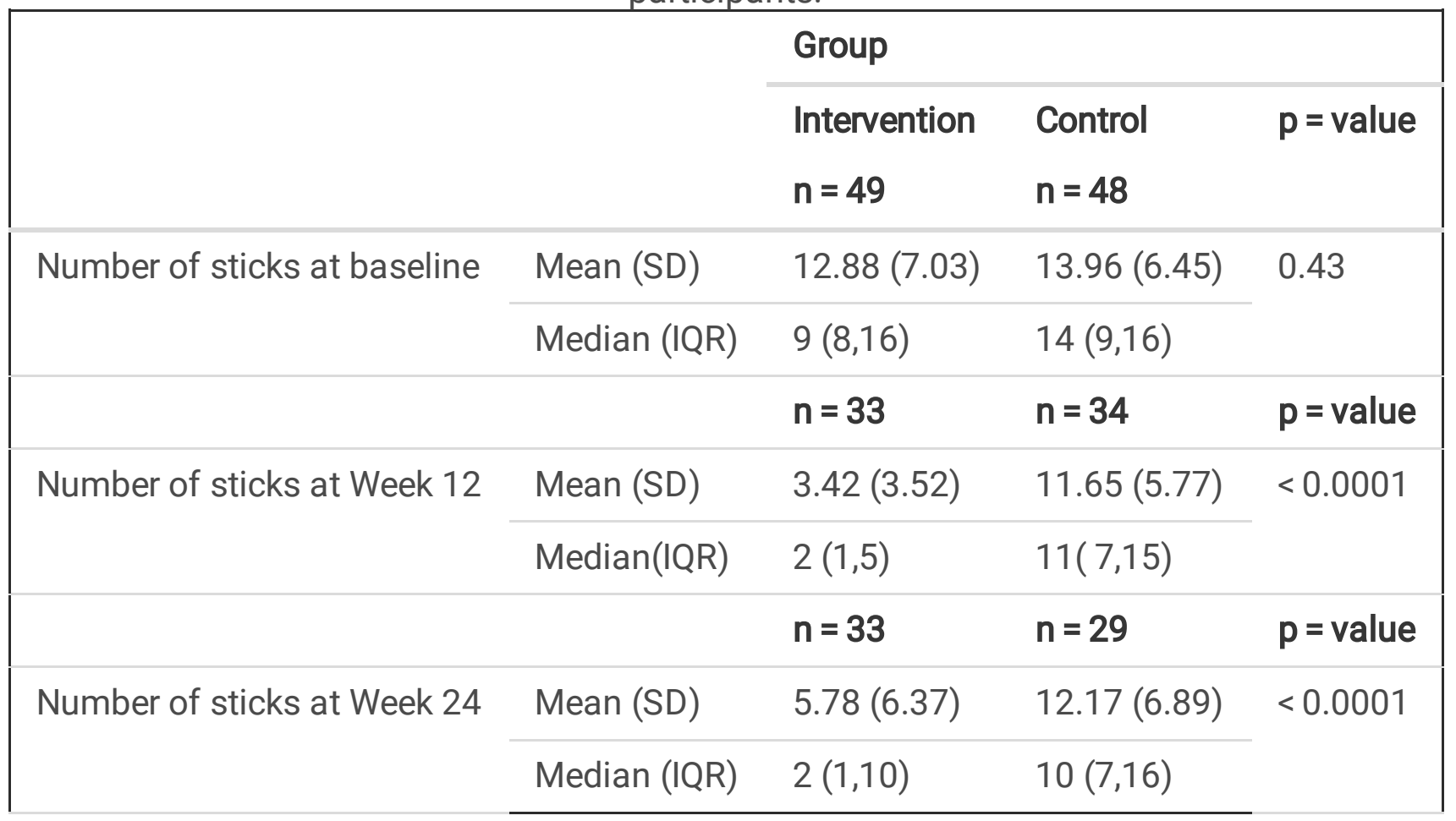

When comparing changes in the amount smoked at the end of the 24-week study period among individuals who completed the study, intervention group participants reduced the number of cigarettes or kuber smoked more than the control group participants (intervention group median [IQR] reduction: 8 [6, 13] cigarettes or kuber vs control group median [IQR] reduction: $2[-2,6]$ cigarettes or kuber, $P<0.0001$, Supplemental Table 3). The unadjusted results showed that participants in the intervention group were almost 14 times more likely to reduce smoking than participants in the control group ( $97.0 \%$ vs $58.6 \%$, HR 13.85 [95\% Cl, 3.95-48.59]). After adjusting for covariates that potentially confound the relationship between the group allocation and tobacco cessation [19], the direction and magnitude of effect were similar (HR 14.92 [95\% Cl, 4.06-54.86], Table 4). 
Table 4

Cox proportional hazards regression models for the outcome of any reduction in smoking among trial participants.

\begin{tabular}{|c|c|c|c|c|c|c|}
\hline \multirow[t]{2}{*}{ Covariates } & \multirow{2}{*}{$\begin{array}{l}\text { Unadjusted } \\
\text { HR }\end{array}$} & \multicolumn{2}{|l|}{$95 \% \mathrm{Cl}$} & \multirow[t]{2}{*}{ Adjusted HR* } & \multicolumn{2}{|l|}{$95 \% \mathrm{Cl}$} \\
\hline & & Lower & Upper & & Lower & Upper \\
\hline Group (Intervention) & 13.85 & 3.95 & 48.59 & 14.92 & 4.06 & 54.86 \\
\hline Age & 0.99 & 0.95 & 1.03 & 0.97 & 0.93 & 1.00 \\
\hline Sex (Males) & 1.99 & 0.92 & 4.34 & 3.03 & 1.16 & 7.92 \\
\hline Baseline Fagerstrom score & 1.01 & 0.85 & 1.19 & 1.25 & 1.02 & 1.52 \\
\hline Use of $A O D$ & 1.05 & 0.54 & 2.03 & 0.79 & 0.40 & 1.59 \\
\hline
\end{tabular}

AOD: Alcohol and other drug use, but not diagnosed as a substance use disorder

\section{Secondary Outcomes: Health-Related Quality of Life (HRQOL)}

Mean HRQOL scores at baseline and 24-week follow-up in the intervention and control groups are reported in Table 5. When comparing the four domains in the instrument (i.e. physical, psychological, social relationships, and environment) at baseline and 24-week follow-up, changes at 24 week follow-up were numerically higher in the intervention group compared to the control group. However, these differences were not statistically significant. 
Table 5

Mean changes in health-related quality of life among the different domains at baseline and end of 24week study period among trial participants.

\begin{tabular}{|c|c|c|c|c|c|c|}
\hline Domains & Duration & Intervention & & Control & & $\begin{array}{l}\text { Intervention vs } \\
\text { Control }\end{array}$ \\
\hline & Period & Mean (SD) & $\begin{array}{l}\mathrm{p}- \\
\text { value }\end{array}$ & Mean(SD) & $\begin{array}{l}\mathrm{p}- \\
\text { value }\end{array}$ & $\mathrm{p}$-value \\
\hline \multirow[t]{2}{*}{ Physical } & Baseline & 12.99(3.19) & \multirow[t]{2}{*}{0.12} & $14.51(1.89)$ & \multirow[t]{2}{*}{0.47} & 0.004 \\
\hline & $\begin{array}{l}\text { 24-week } \\
\text { follow-up }\end{array}$ & $13.90(2.71)$ & & $12.78(2.61)$ & & 0.48 \\
\hline \multirow[t]{2}{*}{ Psychological } & Baseline & $13.27(2.83)$ & \multirow[t]{2}{*}{0.88} & $13.88(2.39)$ & \multirow[t]{2}{*}{0.29} & 0.20 \\
\hline & $\begin{array}{l}\text { 24-week } \\
\text { follow-up }\end{array}$ & $13.62(2.26)$ & & $12.56(2.00)$ & & 0.24 \\
\hline \multirow{2}{*}{$\begin{array}{l}\text { Social } \\
\text { relationships }\end{array}$} & Baseline & $12.65(3.51)$ & \multirow[t]{2}{*}{0.08} & $13.22(2.98)$ & \multirow[t]{2}{*}{0.51} & 0.59 \\
\hline & $\begin{array}{l}\text { 24-week } \\
\text { follow-up }\end{array}$ & $12.81(3.54)$ & & $11.51(2.60)$ & & 0.15 \\
\hline \multirow[t]{2}{*}{ Environment } & Baseline & $12.57(3.18)$ & \multirow[t]{2}{*}{0.44} & $14.56(3.46)$ & \multirow[t]{2}{*}{0.50} & 0.01 \\
\hline & $\begin{array}{l}\text { 24-week } \\
\text { follow-up }\end{array}$ & $13.24(2.84)$ & & $11.94(1.42)$ & & 0.20 \\
\hline
\end{tabular}

Changes in $\mathrm{HRQOL}$ in the intervention and control groups among individuals who completed the 24-week follow-up period are reported in Supplemental Table 4. Participants in the intervention group were more likely to experience greater improvement in physical (30.6\% vs $10.4 \% \mathrm{OR}=3.79[95 \% \mathrm{Cl}, 1.25-11.48]$ ) and environmental health (34.7\% vs 8.3\%, OR $=5.84$ [95\%, 1.79-19.03]) domains ( $P<0.01$ for both), but changes in other domains were similar between groups. Domain-specific, adjusted results are reported in Supplemental Table 5, which showed a similar direction to the overall results with better quality of life in the environment domain among individuals randomized to the study intervention group (adjusted OR $6.46[95 \% \mathrm{Cl} 1.79-23.34])$.

\section{Discussion}

\section{Summary of Results}

Using a controlled clinical trial design, the study sought to determine the efficacy of a group tobacco cessation behavioural intervention among tobacco using patients with concomitant mental illnesses in Kenya on tobacco cessation at 24-week follow-up, and to evaluate the effect of a group tobacco cessation behavioural intervention on HRQOL of patients with mental illnesses.

The main study findings include: 1) participants allocated to the intervention group reported a higher cessation rate and lower number of cigarettes smoked or kuber chewed compared with the control group 
over the study period; 2) adjusted results showed that participants in the intervention group at any point during the study period were almost 14 times more likely to reduce smoking than participants in the control group, though there were a small number of events driving this finding; and 3) intervention group participants reported greater change in HRQOL scores compared with control group participants, though these results were not statistically significant.

\section{Explanation of Results}

There were a greater number of participants in the intervention group who achieved the primary outcome, which was statistically significant at the end of week 12 , but was not statistically significant by the end of the study at 24-weeks. The results could be considered potentially clinically meaningful given the harmful health effects of even light smoking; however, because the study is underpowered to detect true differences we report these results within this limitation. Similar to our findings, a study by Prochaska et al. (2014) evaluated the effects of a motivational tobacco cessation treatment combined with nicotine replacement therapy compared to usual care initiated in inpatient psychiatry. The study showed that abstinence was significantly higher for the intervention group than usual care at 3-months $(13.9 \%$ vs $3.2 \%$ ) and 6 -months ( $14.4 \%$ vs $6.5 \%$ ) at 7-day point prevalence biochemically verified [20]. Due to the high loss to follow-up in this study, strategies to promote retention among study participants are key to better evaluate the intervention's effectiveness.

The study shows frequent quit attempts and reduced numbers of cigarettes smoked during each meeting. Participants were not told to stop tobacco use immediately as the study did not offer nicotine replacement therapy. Gradual smoking reduction can decrease the severity of withdrawal and cravings compared with immediate cessation. Indeed, withdrawal symptoms and cravings are the main deterents to achieving cessation and contributing to relapse [21], and has been shown to predict future abstinence in the schizophrenia population [22]. In cessation attempts, cutting down the number of daily cigarettes smoked may increase quit attempts, while encouraging continued attempts and potentially increasing self confidence and success. A higher confidence in ones cessation efforts are thought to increase the likelihood that a final goal - in this case cessation - will be achieved [23]. Successful smoking cessation is difficult, with as few as $3-5 \%$ successfully quit without assistance, and less than $10 \%$ of all smokers who achieve long term abstinence, succeed after many unsuccessful quit attempts [24].

Most participants were unable to sustain cessation at the end of the 24-week follow-up period. However, some participants were able to reduce the number of sticks they smoked ( $<2$ sticks per day) with a higher rate in the intervention group. It may be possible that a longer period or more frequent doses of the group behavioural intervention may have been needed to achieve a higher cessation rate in these participants. This potential value of longer duration of follow-up or more intensive weekly sessions was supported by participants who requested continuity of the follow up, but this was not feasible.

\section{Comparison with Clinical Guidelines and Prior Research}

Clinical guidelines for tobacco cessation reported by Fiore et al. (2008) recommend more intensive interventions as well as pharmacotherapy to improve cessation outcomes [25]. The findings of this study 
suggest that counselling is feasible and potentially effective. Policies to improve availability, accessibility, and affordability of tobacco cessation pharmacotherapy are needed to help Kenyan tobacco users with mental illness quit. Aveyard and Linson-Hawley (2014), noted that people who are reducing their tobacco consumption are more likely to attempt to quit and to succeed than are those who are not. These authors identified a need to teach people methods to help them reduce tobacco consumption as a strategy to increase the likelihood of achieving successful cessation [26].

Results from de Leon et al. (2005) showed that maintaining tobacco cessation among patients with concomitant mental illness is very difficult. The study, which focused on alcohol, drugs, and smoking cessation, found that almost half (45\%) of people with severe psychiatric illness were able to quit alcohol or drugs, but only $10 \%$ successfully remained quit in a period of one year. This outcome was similar to our study, as $15 \%$ were able to successfully quit at the end of 12 weeks, but only $9 \%$ remained successfully quit at the end of the 24-week study period. People with mental illness mostly have poor outcomes with cessation treatments; there is need to develop new interventions specifically focused to this population [27].

The SCIMITAR study, which was a tobacco cessation intervention incorporating behavioural support and pharmacological aid among persons with mental illness, showed the proportion of participants who quit at 6-months was significantly higher in the intervention group than the control group ( $14 \%$ vs $6 \%, P=$ 0.01). Despite our study not offering pharmacological support, it offered the "cut-down" to quit approach similar to the SCIMITAR trial. The SCIMITAR investigators observed an improvement in physical health in the intervention group at 6-months; however, this difference was no longer evident at 12 months. On the other hand, there was no difference in mental health domains among SCIMITAR participants at six and 12 months [28].

Results from eight clinical trials with treatment periods lasting eight to 12 weeks started in inpatient settings and continued post discharge, have shown smoking quit rates of different cessation intervention, including behavioural and pharmacological interventions, range from 4-22\% among people with mental illnesses [29]. Banham et al. (2010) reviewed eight randomised controlled trials and found similar results to the current study. They found that none of the trials reviewed reported any significant differences between intervention and control groups at the end of follow-up; however, these randomized controlled trials (RCTs) all incorporated nicotine replacement therapy in their interventions. No significant differences was reported between a specialised severe mental illness smoking programme with NRT compared with standard smoking cessation group therapy with NRT at either end of trial or end of followup (one RCT). The review reported greater abstinent rates at trial end for: individual therapy together with NRT compared with usual care (RR $2.74,95 \% \mathrm{Cl} 1.10$ to 6.81 ; one RCT); bupropion together with group therapy compared with placebo with group therapy (RR 4.18, 95\% Cl 1.30 to 13.42; three RCTs); bupropion together with group therapy and nicotine replacement therapy compared with placebo; and group therapy and NRT (RR 2.34, 95\% Cl 1.12 to 4.91; two RCTs) [30]. 
Most of these RCTs had findings almost similar to our study even though most of them incorporated cessation pharmacotherapies. This shows that our study has promise of increased positive outcome, particularly if pharmacotherapies are included.

\section{Strengths and Limitations}

This study has several strengths. First, the study was conducted among a high-burden population in a novel setting and was implemented in participants' usual environments and during regularly scheduled outpatient clinic follow-up days. Second, the study focused on strategies that were readily available and did not have significant direct costs for participants in terms of attending group therapy. Third, the study demonstrated feasibility, acceptability, and a signal of benefit from the intervention suggesting potential benefits with further refinement.

The current study also had important limitations which may influence the certainty of the findings. First, participants self-reported their quit attempts and reduction in amount smoked during every group meeting. Systematic reviews have indicated that self-reports of smoking status are generally accurate unless the participants fear loss of particular benefits if they do not quit [31]. To reduce the risk of ascertainment bias, biochemical verification was conducted on participants who reported complete cessation.

Second, by design, the intervention group met more frequently compared to the control group. Participants may have benefited from the study intervention but may have also been susceptible to the Hawthorne effect, wherein their behaviour changed because of the process of observing the behaviour [32]. In the study, we sought to minimize the effect of this by integrating into usual clinical practice days. We also held intervention sessions on different days than the control groups' clinical practice days, which reduced the risk of contamination. It is arguable but seems unlikely that control participants might have been motivated to quit tobacco if they perceived that the intervention group was receiving special treatment.

Third, the study had a high loss to follow-up rate, and we treated all participants who were lost to follow up as smokers in the intention to treat analysis. This conservative approach is the typical method of handling missing data in smoking cessation trials [33]. The research team tried to contact all participants who were missing before group meetings began. When a participant failed to attend meetings three consecutive times, they were counted as dropped out (lost to follow-up). Higher retention may have led to a larger effect than was observed, though it may be possible that the opposite effect is also true. Fourth, the study did not analyse the actual cost of the intervention. Knowing the actual cost might help with implementation and replication in different mental health care facilities.

\section{Conclusions}

Results from this trial demonstrate feasibility and benefits of a tailored group tobacco behavioural tobacco cessation intervention among mentally ill population with tobacco use dependence in Kenya. 
This study showed that persons with mental illness are willing to quit tobacco use and to engage in tobacco-related research. Results also suggests these individuals can reduce the number of cigarettes used and can improve their health-related quality of life through a group behavioural intervention, even without cessation pharmacotherapies. Future research should evaluate adaptations of the current study to improve retention for longer-term effects across a larger, more diverse population in Kenya, and other sub-Saharan African countries.

\section{List Of Abbreviations}

CSAT- Clinic for Substance Abuse Treatment

DSM- Diagnostic and Statistical Manual of Mental Disorders

FTND- Fagerstrom Test for Nicotine Dependence

ICD- International Classification of Diseases

NACOSTI- National Commission for Science, Technology and Innovation

UoN- University of Nairobi

WHO- World Health Organization

WHOQOL- World Health Organization Quality of Life

HRQOL- Health Related Quality of Life

\section{Declarations}

All methods were carried out in accordance with relevant guidelines and regulations.

\section{Ethics approval and consent to participate}

The study received ethical approval clearance from the University of Nairobi/Kenyatta National Hospital Ethical Review Committee on the 28 ${ }^{\text {th }}$ February 2017 Ref: KNH-ERC/A/68, renewed on April 182018 Ref: $\mathrm{KNH} / \mathrm{ERC} / \mathrm{R} / 87$ and March 292019 Ref: KNH/ERC/R/55. It was then registered at National Commission for Science, Technology and Innovation (NACOSTI)-Ref: NACOSTI/P/18/37962/21104 on 3 May 2018 and retrospectively registered at ClinicalTrials.gov Ref: NCT04013724 on 9 July 2019. All participants signed a consent form before participating in the study.

\section{Consent for publication}

The consent form has a section that mentions that findings from the study will be published and disseminated widely, while ensuring confidentiality and anonymity of participants is retained. All 
participants signed this form thereby giving consent for publication.

\section{Availability of data and material}

The datasets used and/or analysed during the current study are available from the corresponding author on reasonable request.

\section{Competing interests}

YO, MM, MK, FN declare that they have no competing interests. MDH has received grant support from the World Heart Federation to serve as its senior program advisor for the Emerging Leaders program, which is supported by unrestricted educational grants from Boehringer Ingelheim and Novartis with previous support from AstraZeneca and Bupa. MDH also receives support from the American Heart Association, Verily, and AstraZeneca and the American Medical Association for work unrelated to this project.

\section{Funding}

No specific funding for this trial whose costs were borne by the principal investigator.

\section{Authors' contributions}

YO was the principal investigator of the study and designed the implementation. MK, MM, MDH reviewed the proposal and data collection tools and procedures, manuscript. YO took part in the data collection. FN and MK analysed the data. This manuscript paper was written by YO, with input of all co-authors who provided critical revisions. All authors have read and approved the final manuscript.

\section{Acknowledgements}

The authors would like to acknowledge Mathari Referral hospital for their support, and participants for their willingness to participate in the study. They would also like to acknowledge, Morris Atwetwe and Magdalene Micheni for their contributions during participants' recruitment, screening, intake, and registration screening, assessment, recruitment and group facilitation and Nancy Karanja and Justus Okenye who assisted with facilitation of the tobacco cessation groups.

\section{References}

1. Marangu E, Sands N, Rolley J, Ndetei D, Mansouri F. Mental healthcare in Kenya: Exploring optimal conditions for capacity building. Afr J Prm Health Care Fam Med. 2014; 6(1):E1-5.

2. Global Adult Tobacco Survey (GATS). Kenya Report. Ministry of Health. Kenya. 2014. http://www.who.int/tobacco/surveillance/survey/gats/Kenya-report-2014.pdf. Accessed 30 May 2018. 
3. Tobacco Tactics. Kenya-Country Profile. University of Bath. (2020). Retrieved From: https://tobaccotactics.org/wiki/kenya_country_profile/ Accessed 28 April 2020.

4. Cook BL, Wayne GF, Kafali EN, Liu Z, Shu C, Flores M. Trends in smoking among adults with mental illness and association between mental health treatment and smoking cessation. JAMA. 2014; 311(2):172-182. https://doi.org/10.1001/jama.2013.284985.

5. Prochaska, J. J., Das, S., \& Young-Wolff, K. C. Smoking, Mental Illness, and Public Health. Annual Review of Public Health. 2017; 38:165-185.

6. Gfroerer J, Dube SR, King BA, Garrett BE, Babb S, McAfee T. Centers for Disease Control and Prevention (CDC) Vital signs: current cigarette smoking among adults aged $\geq 18$ years with mental illness-United States, 2009-2011. MMWR Morb Mortal Wkly Rep. 2013; 62 (5):81-87.

7. Tam J, Warner K, Meza R. Smoking and the reduced life expectancy of individuals with serious mental illness. Am J. Prev Med. 2016; 51 (6):958-966.

8. Goldenberg M, Danovitch I, IsHaak WW. Quality of life and smoking. Am J. Addict. 2014; 23 (6):54062.

9. Ministry of Public Health and Sanitation, Kenya. National Tobacco Control Action Plan, 2010-2015. Nairobi: Ministry of Public Health and Sanitation. 2010.

10. Ministry of Health, Kenya. National Guidelines for Tobacco Dependence, Treatment, and Cessation. Nairobi: Tobacco control unit, Ministry of Health. 2017.

11. Ratschen E, Britton J, and McNeill A. The smoking culture in psychiatry: Time for change. British Journal of Psychiatry. 2011;198(1):6-7.

12. Ngaruiya, C., Abubakar, H., Kiptui, D. et al.Tobacco use and its determinants in the 2015 Kenya WHO STEPS survey. BMC Public Health .2018; 18:1223.

13. Gichuki J, Opiyo R, Mugyenyi P, Namusisi K. Healthcare providers' level of involvement in provision of smoking cessation interventions in public health facilities in Kenya. Journal of Public Health in Africa.2015; 6:523.

14. Olando $\mathrm{Y}$, Kuria M, Mathai M, Huffman MD. Efficacy of a group tobacco cessation behavioral intervention among tobacco users with concomitant mental illness in Kenya: Protocol for a controlled clinical trial. BMC public health. 2019 Dec 18;19(1). 1700.

15. The Royal Australian College of General Practitioners. Supporting smoking: Guide for health professionals. Melbourne, Australia: Royal College of General Practitioners. 2011.

16. World Health Organization. Strengthening health systems for treating tobacco dependence in primary care: Building capacity for tobacco control: Training package. Geneva, Switzerland: WHO. 2013. 
17. Etter J, Huhuelet P, Perneger TV, Cornuz J. Nicotine Gum Treatment Before Smoking Cessation: A randomized trial. Arch Intern Med. 2009; 169 (11):1028-1034.

18. World Health Organization. Division of Mental Health. WHOQOL-BREF: Introduction, administration, scoring and generic version of the assessment: Field trial version, World Health Organization.1996.

19. Cook BL, Wayne GF, Kafali EN, Liu Z, Shu C, Flores M. Trends in Smoking Among Adults With Mental Illness and Association Between Mental Health Treatment and Smoking Cessation. JAMA. 2014; 311(2):172-182.

20. Prochaska JJ, Hall SE, Delucchi K, Hall SM. Efficacy of initiating tobacco dependence treatment in inpatient psychiatry: a randomized controlled trial. Am J Public Health. 2014;104(8):1557-1565.

21. West RJ, Hajek P, Belcher M. Severity of withdrawal symptoms as a predictor of outcome of an attempt to quit smoking. Psychol Med. 1989; 19:981-5.

22. Evins AE, Cather C, Rigotti NA, Freudenreich O, Henderson DC, Olm-Shipman CM. et al. Two-year follow-up of a smoking cessation trial in patients with schizophrenia: increased rates of smoking cessation and reduction. J Clin Psychiatry. 2004;65(3):307-11.

23. Bandura A. Self-efficacy: toward a unifying theory of behavioural change. Psychol Rev.1977; 84:191-215.

24. Babb S, Malarcher A, Schauer G, Asman K, Jamal A. Quitting smoking among adults - United States, 2000-2015. MMWR. 2017; 65:1457-64.

25. Fiore MC, Jaén CR, Baker TR, et al. Treating Tobacco Use and Dependence: 2008 Update Clinical Practice Guideline. Rockville, MD: U.S. DHHS. Public Health Service. 2008.

26. Aveyard P and Lindson-Hawley N. Should smokers be advised to cut down as well as quit? BMJ. 2014; 348:g2787.

27. de Leon J, Susce MT, Diaz FJ, Rendon DM, Velásquez DM. Variables associated with alcohol, drug, and daily smoking cessation in patients with severe mental illnesses. J Clin Psychiatry. 2005;66(11):1447-1455. doi:10.4088/jcp.v66n1112

28. Gilbody S, Peckham E, Bailey D, et al. Smoking cessation for people with severe mental illness (SCIMITAR+): a pragmatic randomized controlled trial. Lancet Psychiatry. 2019; 6(5):379-390.

29. Kagabo R, Gordon AJ, Okuyemi K. Smoking cessation in inpatient psychiatry treatment facilities: A review. Addict Behv Reports. 2020; 11:100255.

30. Banham L, Gilbody S. Smoking cessation in severe mental illness: What works? Addiction. 2010; 105 (7):1176-1189 
31. Vellicer WF, Prochaska JO, Rossi JS and Snow MG. Assessing outcome in smoking cessation studies. Psychological Bulletin. 1992;111 (1):23-41.

32. McCarney R, Warner J, Iliffe S, Van-Haschen R et al. The Hawthorne effect: a randomised controlled trial. BMC Med Res Methodol. 2007; 7-30.

33. Akl EA, Briel M, You JJ, et al. Potential impact on estimated treatment effects of information lost to follow-up in randomised controlled trials (LOST-IT): systematic review. BMJ. 2012; 344:e2809.

Figures

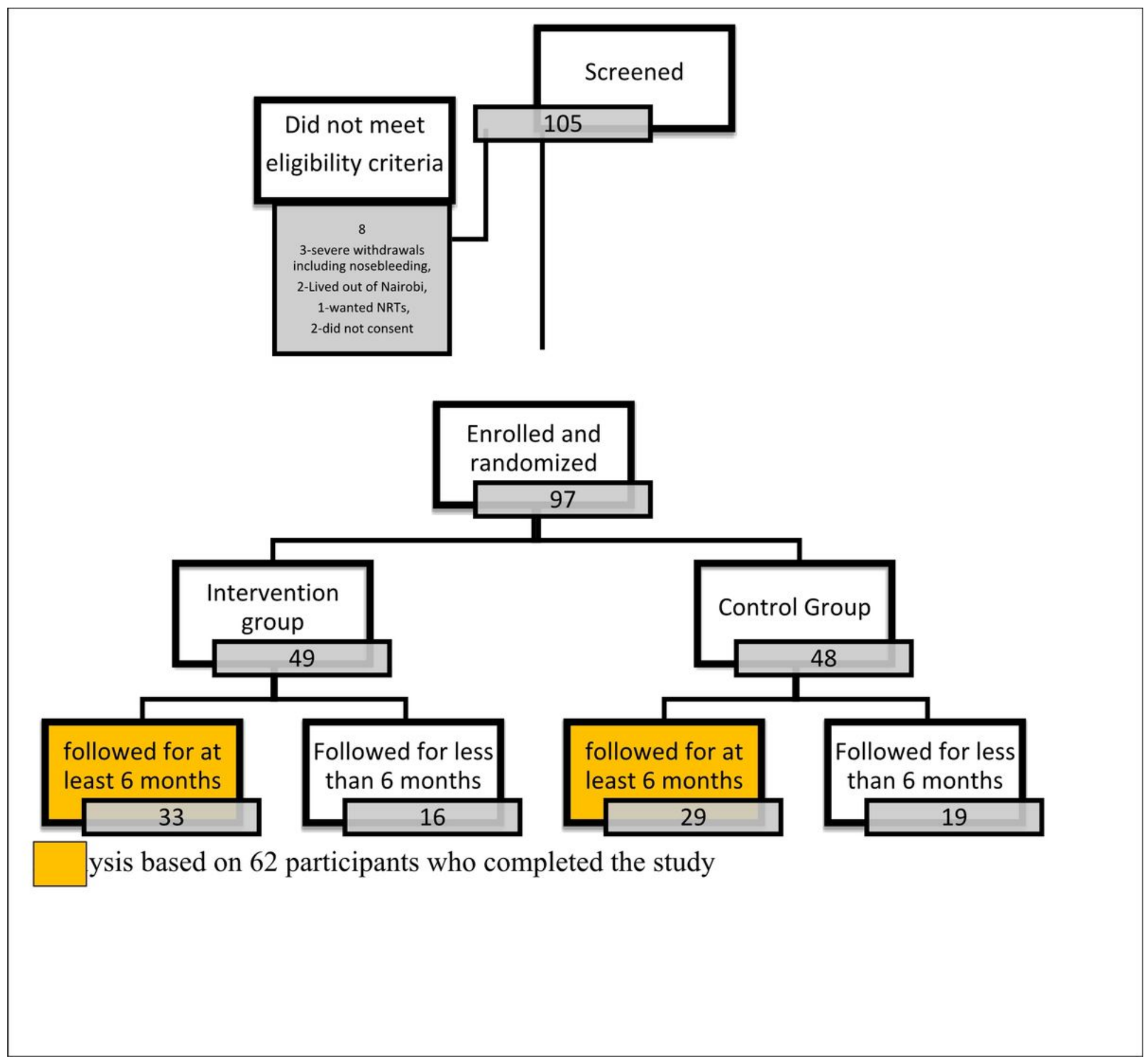




\section{Figure 1}

Clinical trial flow chart for the group behavioural tobacco cessation intervention.

\section{Supplementary Files}

This is a list of supplementary files associated with this preprint. Click to download.

- Supplementarymaterials.docx

- Supplementarymaterials.docx 